\section{References}

${ }^{1}$ Smythe HA, Ogryzlo MA, Murphy EA, Mustard JF. The effect of sulphinpyrazone (Anturan) on platelet economy and blood coagulation in man. Can Med Assoc $\mathcal{F} 1965 ; 92: 818-21$.

2 The Anturane Reinfarction Trial Research Group. Sulfinpyrazone in the prevention of sudden death after myocardial infarction. $N$ Engl F Med $1980 ; 302: 250-6$.

${ }^{3}$ Mitchell JRA. Secondary prevention of myocardial infarction-the present state of the ART. Br Med f 1980;280:1128-30.
${ }^{4}$ Mitchell JRA. Clinical events resulting from thrombus formation. $\mathrm{Br} \mathrm{Med}$ Bull 1978;34:103-6.

${ }^{5}$ Moschos C, Escobinas A, Jorgensen O, Regan T. Effect of sulphinpyrazone on survival following experimental non-thrombotic coronary occlusion. Am f Cardiol 1979;43:372.

${ }^{6}$ Lown B, Wolf $M$. Approaches to sudden death from coronary heart disease. Circulation 1971;44:130-42.

${ }^{7}$ Flear CTG, Hilton P. Hyponatraemia and severity and outcome of myocardial infarction. $B r \operatorname{Med} \mathcal{f} 1979 ; \mathrm{i}: 1242-6$.

(Accepted 18 fuly 1980)

\title{
Actinomyces-like organisms in cervical smears from women using intrauterine contraceptive devices
}

\author{
HELEN L D DUGUID， DAVID PARRATT， ROBERT TRAYNOR
}

\section{Summary and conclusions}

Cervical smears from 293 users of intrauterine contraceptive devices attending family planning clinics in East Fife, Dundee, and Angus were stained by Papanicolaou and Gram's methods and examined for actinomyces-like organisms. Of the 128 women using plastic devices, 40 gave smears positive for these organisms. In contrast only two positive smears were obtained from the 165 women using devices containing copper and none from a control group of 300 women taking oral contraceptives. Colonisation was mure common in women whose plastic devices had been in situ for over two years. Correlations between the presence of these organisms and recorded incidences of pain and both clinical and cytological evidence of inflammation of the lower genital tract were highly significant $(p=0.00001, p<0.00001$, and $p<0.00001$ respectively).

The results suggest that plastic intrauterine contraceptive devices predispose to colonisation by actinomyceslike organisms, particularly after long-term use. Hence if the apparently bacteriostatic action of copper devices is confirmed these should probably be more widely used.

\section{Introduction}

With the widespread use of modern intrauterine contraceptive devices genital actinomycosis is becoming increasingly common. $^{1-3}$ In Britain several actinomycotic tubo-ovarian abscesses have been reported, ${ }^{45}$ and in North America many cases of serious pelvic infection have occurred, including systemic dissemination of the organisms and one death. ${ }^{26} 7$

Gupta in 1972 was the first to identify cytologically colonies of actinomyces-like organisms in cervical smears from women using intrauterine contraceptive devices and, later, with a fluorescent antibody technique, classified most of these as Actinomyces israeli. ${ }^{8-10}$ By 1978 Gupta et al had identified 540 such cases. ${ }^{11}$ Jones et $a l^{12}$ rescreened 300 cervical smears from women using these devices and found actinomyces-like organ-

Cytology Unit, Royal Infirmary, Dundee DD1 9ND

HELEN L D DUGUID, MD, FRCPATH, consultant pathologist

Department of Bacteriology, Ninewells Hospital, Dundee DD2 1UB DAVID PARRATT, MD, MRCPATH, senior lecturer

ROBERT TRAYNOR, FIMLT, chief medical laboratory scientific officer isms in $25.5 \%$ of smears from women attending public health and family planning clinics and $8 \%$ of smears from private patients.

To our knowledge the following report is the first retrospective epidemiological study of the clinical importance of cervical colonisation by these organisms and of their association with various types of intrauterine contraceptive devices.

\section{Patients and methods}

Between March 1978 and March 1979 cervical smears were examined from 293 women using intrauterine contraceptive devices and from a randomly selected control group of 300 women taking oral contraceptives. All women were attending family planning clinics in three adjacent districts (East Fife, Dundee, and Angus). The policy for taking smears differed slightly among the districts, though most of the women were tested at intervals of one to two years. In Fife smears were taken only when the cervix was clinically healthy. If cervicitis was suspected samples were examined bacteriologically. In Angus, in addition to routine cervical smears, cytology was used to confirm a clinical suspicion of cervicitis. In Dundee there was no definite policy.

Of the 293 intrauterine contraceptive devices being worn, 128 were plastic (108 Saf-T-coil, 15 Lippes loop, 2 Dalkon shield, 1 Ota's ring, 2 unknown) and 165 contained copper (157 Gravigard, $8 \mathrm{Cu}-\mathrm{T}$ ).

\section{METHODOLOGY}

Cervical smears were taken under direct vision with an Ayre spatula modified by one of us and the occupational therapy department, Royal Dundee Liff Hospital, to enable the tip to be inserted into the endocervical canal of most parous women (fig 1). Smears were stained by the standard Papanicolaou method and examined by one cytology screener for actinomyces-like organisms and inflammatory changes. Smears positive or suspicious for these organisms were decolorised, washed, restained by Gram's method, and re-examined and the findings categorised as follows.

Positive (positive or suspicious on Papanicolaou staining and Grampositive)-Dense aggregates (microcolonies) of bacillus-like organisms seen with feathering at edges (fig 2). Occasionally smaller, more loosely arranged aggregates (classified as suspicious) observed. After Gram staining, typical branching, beaded, slender Gram-positive filaments seen.

Suspicious (positive or suspicious on Papanicolaou staining and Gram-negative)-After Gram staining, branching and beaded organisms not seen but bacilli of non-branching type or fungal mycelia observed.

Negative-No evidence of actinomyces-like organisms detected on Papanicolaou staining.

Statistical significances were assessed with $\chi^{2}$ tests for $2 \times 2,3 \times 2$, and $4 \times 2$ contingency tables for two-sided departures from the null hypothesis. In the $2 \times 2$ case the continuity correction was applied. 


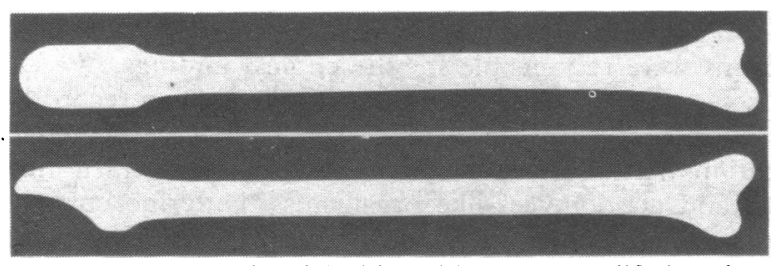

FIG 1-Ayre spatula in original form (above) and modified version (below).

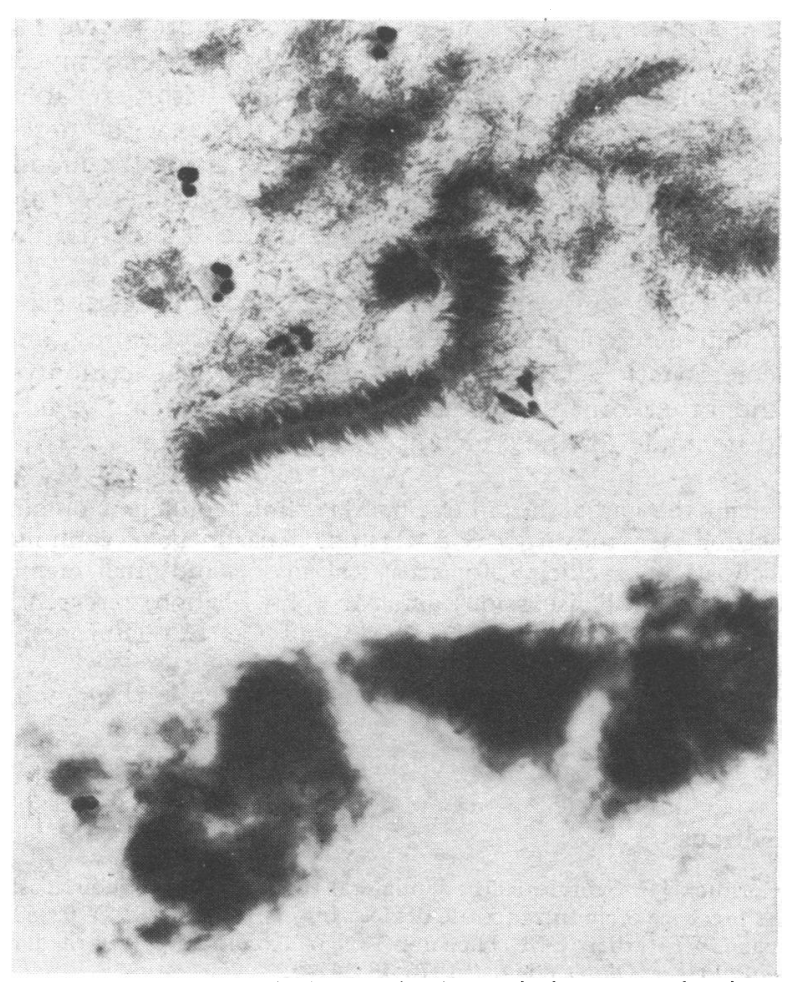

FIG 2-Top: Papanicolaou-stained cervical smear showing typical early appearance of actinomycete-like growth. $\times \mathbf{4 3 0}$ (original magnification). Bottom: Papanicolaou-stained microcolonies of actinomyces-like organisms showing feathering at edges. $\times 430$ (original magnification).

\section{Results}

Of the 128 women wearing plastic intrauterine contraceptive devices, $40(31.3 \%)$ gave cervical smears Gram-positive for actinomyceslike organisms. In contrast only two positive smears $(1.2 \%)$ were obtained from the 165 users of copper devices and none from the 300 controls. This striking difference could not be attributed to varying patient characteristics. Suspicious smears were obtained from 17 women wearing plastic devices $(13.3 \%)$, six wearing copper devices
( $3.6 \%)$, and one of the controls. District differences could be analysed only for the users of plastic devices: of these women, 16 out of 64 $(25 \%)$ tested in Fife, 15 out of $43(35 \%)$ tested in Dundee, and 9 out of $21(43 \%)$ tested in Angus gave positive smears. The excess of positive smears in Angus, however, where smears were always taken when the cervix was clinically unhealthy, did not reach statistical significance. The overall difference between users of copper and plastic devices in the proportions with positive, suspicious, and negative smears was highly significant $(p<0.00001)$.

For the users of intrauterine contraceptive devices the comparison was principally the Saf-T-coil (plastic) versus the Gravigard (copper), though positive smears were also obtained from one of the eight women using $\mathrm{Cu}-\mathrm{T}$ devices and both women using Dalkon shields, which are reportedly associated with a high incidence of infection..$^{13}$

Analysis of the durations of usage of the copper and plastic devices showed that at each duration the prevalence of positive and suspicious smears was greater in the group using plastic devices (table I). Of these women, the proportion with positive smears increased from $8 \%$ within the first two years to $34-38 \%$ in later years. The two positive smears from women using copper devices were obtained within the first two years, and none was obtained from the 48 women who had used these devices for over two years. There was no obvious association between the prevalence of suspicious smears and the time that the devices had been in situ.

From the family planning clinic case records $56(19 \%)$ of all 293 women fitted with intrauterine contraceptive devices had complained of pain (table II), including abdominal pain unrelated to periods ( 31 cases), menstrual or premenstrual pain (14), low back pain (13), and dyspareunia (7). There were significant differences in the incidences

TABLE II-Clinical abnormalities noted in case records of women fitted with intrauterine contraceptive devices whose cervical smears were positive, suspicious, or negative for actinomyces-like organisms. Figures are numbers of women (percentages in parentheses)

\begin{tabular}{llccccc}
\hline \multirow{2}{*}{$\begin{array}{c}\text { Clinical findings } \\
\text { (non-additive) }\end{array}$} & & \multicolumn{4}{c}{ Smear category } \\
\cline { 3 - 7 } & & $\begin{array}{c}\text { Positive } \\
(\mathbf{n}=42)\end{array}$ & $\begin{array}{c}\text { Suspicious } \\
(\mathrm{n}=23)\end{array}$ & $\begin{array}{c}\text { Negative } \\
(\mathrm{n}=228)\end{array}$ & $\begin{array}{c}\text { Total } \\
(\mathrm{n}=293)\end{array}$ \\
\hline Abnormal bleeding & $\ldots$ & $\ldots$ & $11(26)$ & $7(30)$ & $42(18)$ & $60(20)$ \\
Pain... & $\ldots$ & $19(45)$ & $4(17)$ & $33(14)$ & $56(19)$ \\
Evidence of infection & $\ldots$ & $\ldots$ & $19(45)$ & $1(4)$ & $29(13)$ & $49(17)$ \\
\hline
\end{tabular}

Positive $v$ negative smears: incidence of abnormal bleeding $(2 \times 2) \mathrm{p}>0.1$; pain $(2 \times 2) \mathrm{p}=0.0001$; infection $(2 \times 2) \mathrm{p}<0.00001$. Positive $v$ suspicious smears:

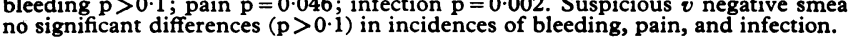

TABLE III-Cytological findings in users of intrauterine contraceptive devices whose smears were positive, suspicious, or negative for actinomyces-like organisms (percentages in parentheses)

\begin{tabular}{|c|c|c|c|c|}
\hline \multirow{2}{*}{ Cytological findings } & \multicolumn{4}{|c|}{ Smear category } \\
\hline & Positive & Suspicious & Negative & Total \\
\hline $\begin{array}{l}\text { Severe inflammation } \\
\text { Moderate inflammation } \\
\text { Pus only; normal epithelial cells . } \\
\text { Clean smear } \quad \ldots\end{array}$ & $\begin{array}{l}19(45) \\
10(24) \\
11(26) \\
2(5)\end{array}$ & $\begin{array}{l}8(35) \\
7(30) \\
6(26) \\
2(9)\end{array}$ & $\begin{array}{l}21(9) \\
29(13) \\
99(43) \\
79(35)\end{array}$ & $\begin{array}{r}48(16) \\
46(16) \\
116(40) \\
83(28)\end{array}$ \\
\hline Total & $42(100)$ & $23(100)$ & $228(100)$ & $293(100)$ \\
\hline
\end{tabular}

Positive $v$ negative smears $(4 \times 2): \mathrm{p}<0.00001$. Suspicious $v$ negative smears $(4 \times 2)$ : $p=0.00006$
$(p>0 \cdot 1)$

TABLE I-Durations of usage of copper and plastic intrauterine contraceptive devices in women with cervical smears positive, suspicious, and negative for actinomyces-like organisms. Figures are numbers of women (percentages in parentheses)

\begin{tabular}{|c|c|c|c|c|c|c|c|c|}
\hline \multirow{2}{*}{$\begin{array}{c}\text { Duration } \\
\text { of use } \\
\text { (years) }\end{array}$} & \multicolumn{4}{|c|}{ Copper device } & \multicolumn{4}{|c|}{ Plastic device } \\
\hline & Positive & Suspicious & Negative & Total & Positive & Suspicious & Negative & Total \\
\hline $\begin{array}{r}<2 \\
2- \\
4- \\
>6\end{array}$ & $2(2)$ & $\begin{array}{l}5(4) \\
1(3)\end{array}$ & $\begin{array}{c}110(94) \\
34(97) \\
11(100) \\
2(100)\end{array}$ & $\begin{array}{r}117 \\
35 \\
11 \\
2\end{array}$ & $\begin{array}{c}2(8) \\
15(38) \\
11(34) \\
12(38)\end{array}$ & $\begin{array}{l}4(16) \\
6(15) \\
4(13) \\
3(9)\end{array}$ & $\begin{array}{l}19(76) \\
18(46) \\
17(53) \\
17(53)\end{array}$ & $\begin{array}{l}25 \\
39 \\
32 \\
32\end{array}$ \\
\hline Total & $2(1)$ & $6(4)$ & $157(95)$ & 165 & $40(31)$ & $17(13)$ & $71(55)$ & 128 \\
\hline
\end{tabular}

Copper $v$ plastic devices $(2 \times 2$ contingency table, positive and suspicious smears pooled $):<2$ years $p=0.014 ; 2-4$ years $\mathrm{p}=0.00001 ; 4-6$ years $\mathrm{p}=0.014 ;>6$ years, insufficient numbers. 
of pain between women with positive smears and those with suspicious and negative smears $(\mathrm{p}=0.046$ and $\mathrm{p}=0.0001$ respectively). Clinical evidence of infection had been recorded in $49(17 \%)$ of the 293 women (table II), including purulent or foul discharge (38 cases), cervicitis or vaginitis (15), and tender uterus (4). These signs were highly significantly more common in the women with positive smears than in those with suspicious and negative smears $(p=0.002$ and $\mathrm{p}<0.00001$ respectively). The incidence of abnormal bleeding did not differ significantly $(p>0 \cdot 1)$ with smear category.

Table III shows the cytological findings in the 293 women with smears positive, suspicious, or negative for actinomyces-like organisms. Cervicitis was diagnosed when, in addition to pus and often blood, the epithelial cells showed reactive changes. The inflammation was graded severe when evidence of epithelial hyperplasia was accompanied by regeneration or repair (regenerative hyperplasia or immature squamous metaplasia) and moderate when only hyperplasia was seen. Severe inflammation was found in $19(45 \%)$ of the 42 smears positive for actinomyces-like organisms, $8(35 \%)$ of the 23 suspicious smears, and $21(9 \%)$ of the 228 negative smears. Moderate inflammation was present in $10(24 \%), 7(30 \%)$, and $29(13 \%)$ of the three categories of smears respectively. In contrast $2(5 \%)$ of the positive smears, $2(9 \%)$ of the suspicious smears, and $79(35 \%)$ of the negative smears were clean cytologically.

\section{Discussion}

We found a highly significant difference in prevalence of cervical colonisation by actinomyces-like organisms between women wearing plastic and copper-containing intrauterine contraceptive devices $(p<0.00001)$. Clinically evident infection with other organisms is more commonly found shortly after insertion,,$^{14-16}$ the thread attached to the device being a possible route of infection..$^{17}$ Our data and those of others, ${ }^{36}{ }^{10}$ however, suggest that infection with actinomyces-like organisms is associated with long-term (over two years) usage of a plastic device. Thirty-eight of all 42 women with smears positive for these organisms had been using a plastic device for over two years.

There are two possible explanations for the protection that the copper device apparently provides against infection with actinomyces-like organisms. Copper salts have a weakly antimicrobial and antifungal action, ${ }^{18} 19$ and bacterial contamination of uterine cavities is reportedly less with copper than with other devices. $^{20}$ In 1905 Bevan ${ }^{21}$ described successfully treating the then usually fatal abdominal actinomycosis with oral and locally applied copper salts. Furthermore, copper is initially eluted from intrauterine contraceptive devices at about $50 \mu \mathrm{g}$ daily, with a lower rate of elution during the second year. ${ }^{16}$ The local copper concentration in the uterus may therefore remain high enough to inhibit or destroy actinomycetes and possibly other organisms.

A second explanation is associated with the mechanisms of infection. Actinomycetes, which exist as commensals in the mouth and possibly the bowel, ${ }^{22}$ are generally regarded as requiring a foreign body and a symbiotic existence with other, often anaerobic organisms to establish infection. ${ }^{6} 10$ Superficial disintegration of intrauterine contraceptive devices occurs with time, ${ }^{23}$ and progressive calcium encrustation on portions of the device in close contact with the tissues may occur. ${ }^{24}$ We suggest that these often calcium-encrusted fragments may be the foreign bodies necessary for the growth of actinomycetes. Such material has been detectedalong the surface of the endometrium, in a tuboovarian actinomycotic abscess, ${ }^{3}$ and associated with the aggregates of organisms in cervical smears. ${ }^{10} \mathrm{We}$ often find such amorphous brown-stained material in smears from users of these devices and also similar, tiny fragments in the centre of aggregates of actinomyces-like organisms. As copper devices have less exposed surface area of plastic than plastic devices ${ }^{16}$ and should be replaced every two years they may produce fewer of these fragments than plastic devices, which are not regularly replaced.

In our series of women with plastic and copper devices in situ the prevalence of infection with actinomyces-like organisms was associated with a difference in symptoms. Pain and clinical evidence of infection were over three times as common in the women with positive smears than in the women with negative smears regardless of the type of device. This suggests that the organisms were responsible for the clinical findings. We could not assess the severity of the pain, which had been recorded by several different observers. Other workers have also noted an association between minor symptomatic uterine tract inflammation and actinomyces-like organisms in uterine curettings, cervical smears, and biopsy specimens. ${ }^{6}>91022$ The few women reported to have tubo-ovarian actinomycosis presumably had widespread infection.

Cytological evidence of severe cervical inflammation in the women with positive and suspicious smears was about five and four times as common respectively as in the women with negative smears. Hence copper may exert a protective effect against infection with other organisms as well as actinomycetes.

Papanicolaou-stained cervical smears are highly reliable in detecting cervicitis and identifying women with possible infection with actinomyces-like organisms. ${ }^{10}$ Using the modified spatula we have found an increased prevalence of these organisms and conclude that it is essential to sample the lower endocervical canal.

Further work on both the clinical and bacteriological aspects of actinomycete colonisation of the cervix is proceeding, and if the bacteriostatic action of copper against cervical actinomyceslike and other organisms can be shown convincingly, a case should be made for the wider use of copper devices.

We thank the staff of the family planning clinics for help in obtaining material for this study; Mr S A Ogston, department of community and occupational medicine, for statistical advice, and other members of staff for helpful discussion; and $\mathrm{Mr}$ John Shelton, research and development division of G D Searle and Co Ltd (Europe), for statistical analysis.

Requests for reprints should be sent to Dr Helen L D Duguid.

\section{References}

${ }^{1}$ McCormick JF, Scorgie RDF. Unilateral tubo-ovarian actinomycosis in the presence of an intrauterine device. Am $\mathcal{F}$ Clin Pathol 1977;68:622-6.

2 Lomax CW, Harbert GM, Thornton WN Jr. Actinomycosis of the female genital tract. Obstet Gynecol 1976;48:341-6.

3 Schiffer MA, Elguezabal A, Sultana M, Allen AC. Actinomycosis infections associated with intrauterine contraceptive devices. Obstet Gynecol 1975; 45:67-72.

4 Purdie DW, Carty MJ, McLeod TIF. Tubo-ovarian actinomycosis and the IUCD. Br Med F 1977 ;ii: 1392.

${ }^{5}$ Charnock $M$, Chambers TJ. Pelvic actinomycosis and intrauterine contraceptive devices. Lancet $1979 ; \mathrm{i}: 1239-40$.

${ }^{6}$ Hager WD, Majmudar B. Pelvic actinomycosis in women using intrauterine contraceptive devices. Am $\mathcal{f}$ Obstet Gynecol 1979;133:60-3.

7 Schiffer MA, Elguezabal A, Allen AC. Actinomycosis infections associated with intrauterine contraceptive devices and a vaginal pessary. Advances in Planned Parenthood 1978;12:183-92.

${ }^{8}$ Gupta PK, Hollander D, Frost JK. Actinomycetes in cervicovaginal smears: an association with IUCD usage. Acta Cytol (Baltimore) 1976; $20: 295-7$.

${ }^{9}$ Spence MR, Gupta PK, Frost JK, King TM. Cytologic detection and clinical significance of Actinomyces israelii in women using intrauterine contraceptive devices. Am $\mathcal{f}$ Obstet Gynecol 1978;131:295-8.

10 Bhagavan BS, Gupta PK. Genital actinomycosis and intrauterine contra ceptive devices. Cytopathologic diagnosis and clinical significance. Hum Pathol 1978;9:567-78.

1 Gupta PK, Erozan YS, Frost JK. Actinomyces and the IUD: an update. Acta Cytol (Baltimore) 1978;22:281-2.

12 Jones MC, Buschmann BO, Dowling EA, Pollock HM. The prevalence of actinomycetes-like organisms found in cervicovaginal smears of 300 IUD wearers. Acta Cytol (Baltimore) $1979 ; 23: 282-6$.

13 Tatum HJ, Schmidt FH, Phillips D, McCarty M, O'Leary WM. The Dalkon shield controversy. $7 A M A 1975 ; 231: 711-7$.

14 Weström L, Bengtsson LP, Nordh P-A. The risk of pelvic inflammatory disease in women using intrauterine contraceptive devices as compared to non-users. Lancet 1976 ;ii :221-4.

15 Osser S, Liedholm P, Gullberg B, Sjöberg N-O. Risk of pelvic inflammatory disease among intrauterine device users irrespective of previous pregnancy. Lancet $1980 ; \mathrm{i}: 386-8$.

${ }^{16}$ Ramaswamy S, Smith T. Practical contraception. Tunbridge Wells: Pitman Medical, 1976:57-73. 
17 Sparks RA. Problems with IUCD tails. Br Med f 1977;ii:1351-2.

18 Cohen L, Thomas G. Copper versus the gonococcus in vivo. Br $\mathcal{F}$ Vener Dis $1974 ; 50: 364-6$.

19 Martindale W. In: Wade A, ed. The extra pharmacopoeia. 27th edn. London: The Pharmaceutical Press, 1977:893-6.

${ }^{20}$ Buckingham MS, Sparks RA, Watt PJ, Elstein M. Pelvic infection and intrauterine devices. $\mathrm{Br}$ Med $\mathcal{F} 1976$;ii :942-3.

${ }^{21}$ Bevan AD. Treatment of actinomycosis and blastomycosis with copper salts. F AMA $1905 ; \mathbf{4 5}: 1492-3$.
${ }^{22}$ Luff RD, Gupta PK, Spence MR, Frost JK. Pelvic actinomycosis and the intrauterine contraceptive device. A cytohistomorphologic study. $A m \mathcal{F}$ Clin Pathol 1978;69:581-6.

${ }^{23}$ Gupta PK, Malkani PK, Bhasin K. Cellular response in the uterine cavity after IUD insertion and structural changes in the IUD. Contraception $1971 ; 4: 375-84$.

${ }^{24}$ Johnson AB Jr, Maness RF, Wheeler RG. Calcareous deposits formed on IUDs in human exposures. Contraception 1976;14:507-17.

(Accepted 26 fune 1980)

\title{
Sodium and potassium intake and blood pressure
}

\author{
PETER BURSTYN， DEE HORNALL，CAROL WATCHORN
}

\section{Summary and conclusions}

Sodium and potassium intakes were increased in normotensive volunteers to assess the effects on their blood pressures. An approximately threefold increase in sodium intake for eight days had no effect on the blood pressures of seven volunteers, while a two-stage increase in potassium intake, by about $\mathbf{4 0 \%}$ for eight days and a further $55 \%$ for 14 days, had no effect on the blood pressures of 21 volunteers. Renal electrolyte excretions and the blood pressures of all 28 subjects showed no statistically significant correlations between either sodium or potassium excretion and blood pressure. A weak negative correlation was found between the sodium: potassium ratio and systolic pressure.

The small reductions in sodium intake and increases in potassium intake that might be achieved through propaganda and changes in food processing are unlikely to lower mean blood pressure in Western societies.

\section{Introduction}

Most authors of review articles have condemned the highsodium, low-potassium diets of Western man. ${ }^{1-3}$ Sasaki blames the hypertension of the Japanese on their high sodium intake and suggests that areas in Japan whose populations have less hypertension than average may be protected by their high potassium intakes. ${ }^{4}$ Nevertheless, several authors have failed to find any relation between sodium intake and blood pressure in five different countries, ${ }^{5-10}$ and very recent reviews have tended to agree that the case against sodium has not been completely proved. ${ }^{11-13}$ On the other hand, the antihypertensive effect of potassium has been shown only in children consuming a great deal of sodium ${ }^{14}$ and in rats with salt-induced hypertension. ${ }^{15}$

Raised intakes of sodium may cause high blood pressures in man, ${ }^{1617}$ but this may not be a general response of the whole population. ${ }^{18} 19$ So far the protective effects of potassium have been shown only in cases of salt-induced hypertension. Nevertheless, it has been suggested that small changes in sodium ${ }^{20}$ and potassium intake ${ }^{21}$ may cause changes in the blood pressures of normal individuals. We have observed the effects of increasing the sodium intake and the potassium intake on the blood pressures of two groups of normotensive volunteers.

\footnotetext{
School of Biochemical and Physiological Sciences, University of Southampton, Southampton S09 3TU

PETER BURSTYN, PHD, lecturer in physiology

DEE HORNALL, BSC, final-year science studen

CAROL WATCHORN, BSC, final-year science student
}

\section{Subjects and methods}

Twenty-eight normotensive volunteers took part in the study. Seven subjects (three women, four men aged 20-35 years) increased their sodium intake for eight days. The three women and two of the men took 25 Ciba Slow Sodium tablets $(600 \mathrm{mg}$ or $10 \mathrm{mmol} \mathrm{NaCl}$ each) daily. The two remaining men, whose renal sodium excretion was higher than that of the others, took 30 tablets daily. The experimental period was preceded and followed by eight-day control periods. All urine produced during the 24 days was collected, the volume and time of each micturition noted, and a small sample preserved for analysis. The urine samples were analysed for sodium and potassium using a Corning 435 flame photometer. The results were expressed as mean daily excretions of sodium and potassium for the various periods. Changes in all variables during the experimental period were compared with control values using the paired $t$ test.

Twenty-one subjects (11 women, 10 men aged 20-47 years) increased their potassium intake for 22 days. For eight days the subjects replaced their table salt with a mixture of equal parts of commercial table salt and potassium chloride. This was followed by 22 days during which the 11 women took eight Ciba Slow K tablets ( $600 \mathrm{mg}$ or $8 \mathrm{mmol} \mathrm{KC1}$ ) daily while the 10 men took 10 tablets daily. The experimental periods were preceded by a 14-day control period and followed by a 10-day control period. Urine was collected as above, but only for four 48-hour periods, one towards the end of each control and experimental period. Analysis was carried out as above.

During the study all the subjects had their blood pressure measured two or three times a week. They also refrained from strenuous activity, which might have resulted in a large electrolyte loss in the sweat, during the experiment. All blood pressures were measured using a Hawksley random zero sphygmomanometer, using the fifth Korotkoff sound as the diastolic pressure. The subjects were seated quietly for 10 minutes before the measurements. Each blood pressure measurement was the mean of three cuff inflations. Subjects were asked to clench their fist gently between inflations to reduce the possibility of diastolic pressure distortion through the pooling of venous blood.

\section{Results}

In the first experiment sodium intake was increased sufficiently to raise the renal sodium excretion by $190 \%$ for eight days. This change in sodium intake had no significant effect on either systolic or diastolic blood pressure (table I). While sodium intake was raised there was a slight increase in renal potassium excretion.

In the second experiment the potassium intake was increased in two stages. The first stage increased renal potassium excretion by $40 \%$ for eight days while the second stage caused a further increase of $55 \%$ for 14 days. Although the renal sodium excretion was expected to diminish slightly during the first stage, when table salt was replaced by a mixture of sodium chloride and potassium chloride, this did not occur. Neither change in potassium intake had any effect on either systolic or diastolic blood pressure (table II). There -was a small statistically significant fall in the pulse pressure during both periods of increased potassium intake. 